\title{
Multi-species consumer jams and the fall of guarded corals to crown-of-thorns seastar outbreaks [version 1; peer review: 2
}

\section{approved]}

\author{
Mohsen Kayal(Đ1,2, Jane Ballard³, Mehdi Adjeroud4 \\ ${ }^{1}$ UPVD-CNRS, Centre de Formation et de Recherche sur les Environnements Méditerranéens (CEFREM), UMR 5110, Perpignan, \\ 66860, France \\ ${ }^{2}$ Centre de Recherche sur les Ecosystèmes Marins (CREM), Port-Barcarès, 66420, France \\ ${ }^{3}$ National Estuarine Research Reserve Association (NERRA), Wells, ME, 04090, USA \\ ${ }^{4}$ Institut de Recherche pour le Développement (IRD), UMR-9220 ENTROPIE, Perpignan, 66860, France
}

V1 First published: 13 Nov 2017, 6:1991

https://doi.org/10.12688/f1000research.13118.1

Latest published: 02 Mar 2018, 6:1991

https://doi.org/10.12688/f1000research.13118.2

\begin{abstract}
Outbreaks of predatory crown-of-thorns seastars (COTS) can devastate coral reef ecosystems, yet some corals possess mutualistic guardian crabs that defend against COTS attacks. However, guarded corals do not always survive COTS outbreaks, with the ecological mechanisms sealing the fate of these corals during COTS infestations remaining unknown. In August 2008 in Moorea (17.539 $\mathrm{S}, 149.830^{\circ}$ W), French Polynesia, an unusually dense multi-species aggregation of predators was observed feeding upon guarded corals following widespread coral decline due to COTS predation. Concurrent assaults from these amplified, mixed-species predator guilds likely overwhelm mutualistic crab defense, ultimately leading to the fall of guarded corals. Our observations indicate that guarded corals can sustain devastating COTS attacks for an extended duration, but eventually concede to intensifying assaults from diverse predators that aggregate in high numbers as alternative prey decays. The fall of guarded corals is therefore suggested to be ultimately driven by an indirect trophic cascade that leads to amplified attacks from diverse starving predators following prey decline, rather than COTS assaults alone.
\end{abstract}

\section{Keywords}

Predator outbreak, Acanthaster, Mutualistic defense, Guardian crab, Trapezia, Mixed-species predator guild, Trophic cascade, Density dependence.

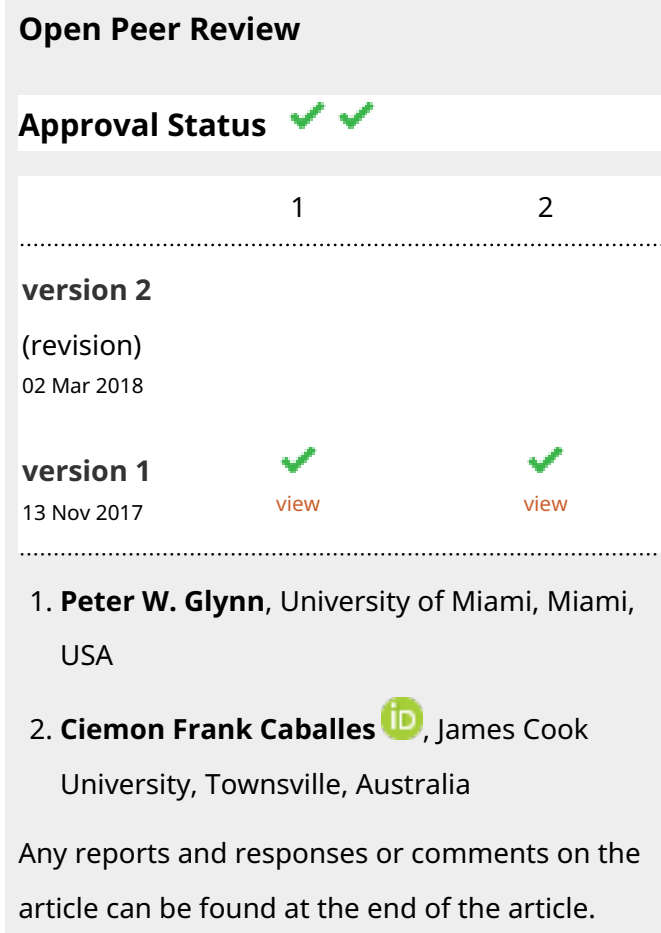


Corresponding author: Mohsen Kayal (mohsen.kayal@gmail.com)

Author roles: Kayal M: Conceptualization, Investigation, Visualization, Writing - Original Draft Preparation; Ballard J: Writing - Original Draft Preparation, Writing - Review \& Editing; Adjeroud M: Funding Acquisition, Project Administration, Resources, Supervision, Writing - Review \& Editing

Competing interests: No competing interests were disclosed.

Grant information: Mohsen Kayal's Ph.D. studies were supported by grants from Polynésienne des Eaux and Planète Urgence. The funders had no role in study design, data collection and analysis, decision to publish, or preparation of the manuscript.

Copyright: (c) 2017 Kayal $\mathrm{M}$ et al. This is an open access article distributed under the terms of the Creative Commons Attribution License, which permits unrestricted use, distribution, and reproduction in any medium, provided the original work is properly cited.

How to cite this article: Kayal M, Ballard J and Adjeroud M. Multi-species consumer jams and the fall of guarded corals to crown-ofthorns seastar outbreaks [version 1; peer review: 2 approved] F1000Research 2017, 6:1991

https://doi.org/10.12688/f1000research.13118.1

First published: 13 Nov 2017, 6:1991 https://doi.org/10.12688/f1000research.13118.1 


\section{Introduction}

Identifying ecological processes that drive species trajectories is a prerequisite for ecosystem management. However, community dynamics are sometimes governed by unexpected, indirect interactions and complex emergent properties that can cause runaway responses and abrupt ecological shifts (Silliman et al., 2013; Terborgh \& Estes, 2010). Outbreaks of the coral predator crownof-thorns seastar (COTS) cause widespread coral mortality across the Indo-Pacific Ocean (Pratchett et al., 2014) with often drastic impacts on diverse reef communities (Kayal et al., 2012). However, some coral species possess mutualistic allies that can deter COTS predation. In particular, trapeziid crabs inhabiting large pocilloporids are known for their ability to effectively defend their host corals from COTS assaults (Glynn, 2013; McKeon \& Moore, 2014), although guarded pocilloporids do not always survive COTS outbreaks (Leray et al., 2012; see Figure 1). Despite increasing understanding of factors determining coral susceptibility to COTS predation (Glynn, 1976; Kayal et al., 2011; Kayal \& Kayal, 2017; Pratchett, 2001; Rouzé et al., 2014), the processes sealing the fate of guarded corals during outbreaks have remained unknown. Here we provide insights into the ecological mechanisms underlying the fall of guarded corals during predatory COTS outbreaks.

\section{Methods}

Our observations were performed at the peak of an intense crown-of-thorns seastar (COTS) outbreak that decimated coral communities around the island of Moorea $\left(17.539^{\circ} \mathrm{S}\right.$, $149.830^{\circ} \mathrm{W}$ ), French Polynesia, between 2003 and 2010. General patterns in propagation of COTS swarms around the island, and impacts on corals and other reef communities were described by Kayal et al. (2012); Kayal et al. (2017). Here, we provide complementary observations that unveil processes leading to the fall of large pocilloporid assemblages that benefit from "anti-COTS" mutualistic defense, the so-called guarded corals. In Moorea, these assemblages are dominated by Pocilloporida eydouxi, a species that hosts trapeziid crabs able to deter COTS predation (Leray et al., 2012; McKeon \& Moore, 2014; Figure 1). Our observations were performed using SCUBA on the outer reef slope at Tiahura where the COTS outbreaks in Moorea were initiated and had particularly detrimental impacts (Kayal et al., 2012).

\section{Results and discussion}

In August 2008 at $12 \mathrm{~m}$ depth on Tiahura reef, we observed an unusually dense aggregation of coral-eating butterflyfishes jamming around guarded pocilloporids, the last coral bastions that had yet resisted swarms of the predatory seastar (Figure 2, Supplementary Image 1). Widespread coral decline had previously wiped out much of resident populations of coral-feeding butterflyfishes (Kayal et al., 2012), pushing starving survivors to aggregate around the guarded corals. The aggregation of 9 butterflyfishes within a single square-meter (9 fish. $\mathrm{m}^{-2}$ ), as captured in Figure 2, was particularly surprising, as density of the coral-feeding butterflyfish assemblage on this reef location

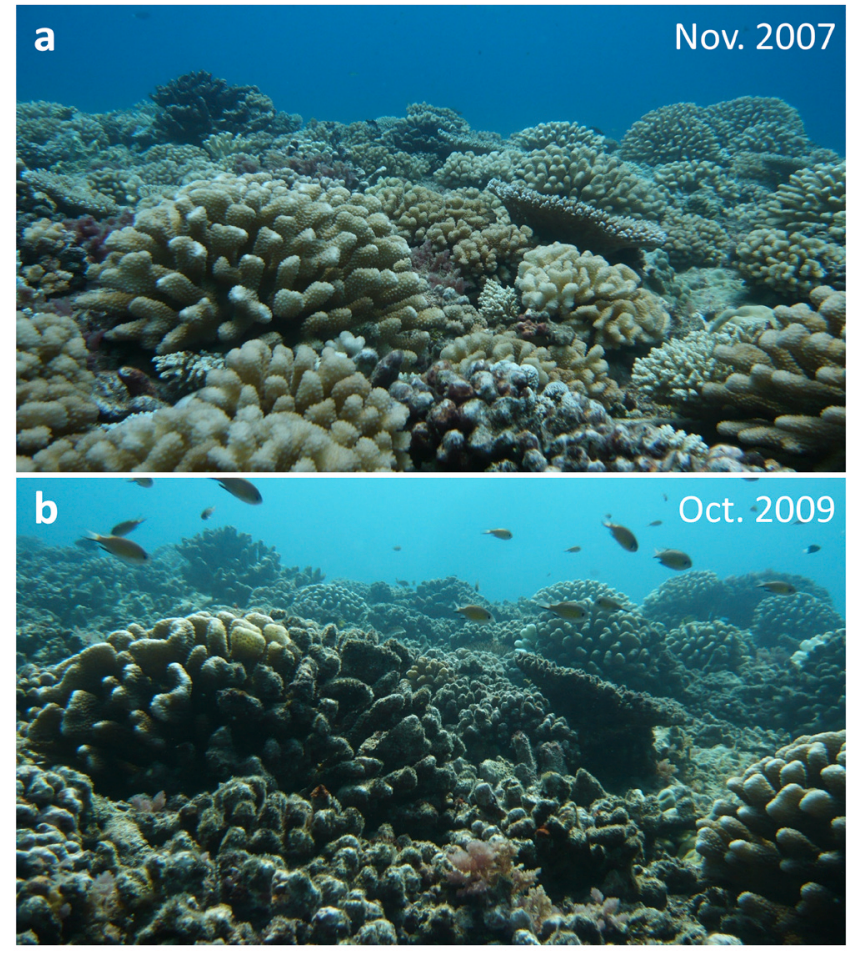

Figure 1. Widespread coral decline and survival of guarded corals that partially or fully resisted seastar predation. Pictures were taken at $6 \mathrm{~m}$ depth on Tiahura reef in Moorea, French Polynesia, before (a) and after (b) this location was invaded by crown-of-thorns seastar (COTS) swarms. White feeding scars characteristic of recent COTS predation can be seen on several of the guarded coral colonies (Pocillopora eydouxi) in $\mathbf{b}$ 


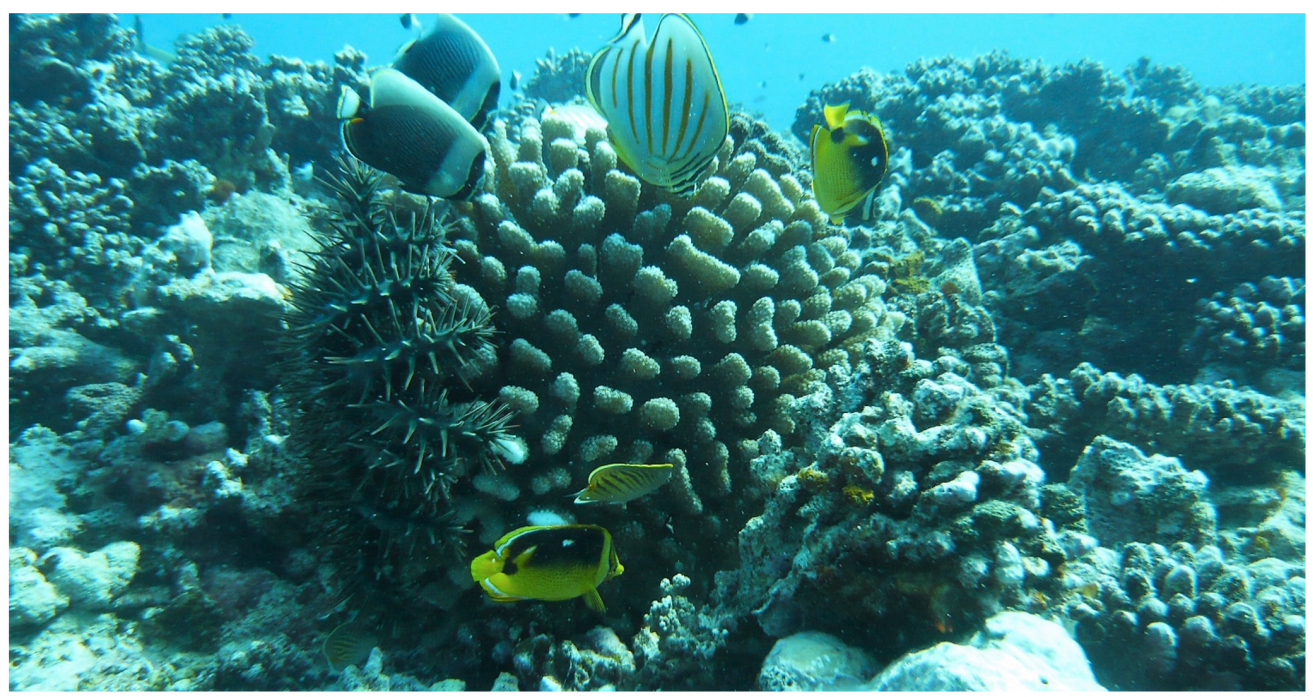

Figure 2. Aggregation of a diversified guild of 10 macro-predators simultaneously feeding upon a guarded coral. This aggregation was observed following widespread coral decline (note the absence of live coral in the background) in August 2008 at $12 \mathrm{~m}$ depth on Tiahura reef in Moorea, French Polynesia. The predator guild was composed of a crown-of-thorns seastar (COTS) and nine butterflyfishes from species Chaetodon ornatissimus, $C$. pelewensis, $C$. quadrimaculatus, $C$. reticulatus. White feeding scars characteristic of recent COTS predation can be seen on the guarded coral (Pocillopora eydouxi).

had dropped to the much lower average value of $4.3 \pm 0.9 \mathrm{SE}$ fish. $200 \mathrm{~m}^{-2}$ (surveyed in June 2008, equivalent to 0.02 fish. $\mathrm{m}^{-2}$ ). The observed aggregation thus represented a more than 400times concentration of the predation pressure exerted by the butterflyfishes, and was targeting a guarded pocilloporid that was already under attack by COTS (Figure 2, Supplementary Image 1).

Guarded pocilloporids in Moorea have shown the ability to resist devastating COTS predation for several years (McKeon \& Moore, 2014; Figure 1). However, concurrent assaults from such locally amplified, mixed-species predatory guilds likely overwhelm the ability of trapeziid crabs and other exo-symbionts to defend host pocilloporids, ultimately causing the fall of guarded corals. Indeed, coral occupation by mutualist communities is determined by strict rules of territoriality and competition (Glynn, 2013; Leray et al., 2012), which limits the abundance of inhabiting guardians in host colonies, and therefore their ability to sustain predatory assaults. Coral decline has already been identified as an engine of COTS movements and prey selection during outbreaks (Kayal et al., 2011; Kayal et al., 2012; Silliman et al., 2013). Our observations suggest that further cascading effects include aggregating diverse predators in numbers surpassing mutualistic defenses, eventually leading to the collapse of guarded corals. We therefore advocate the importance of controlling COTS outbreaks at the earliest stages, before trophic cascades could lead to a runaway collapse of coral communities.

\section{Competing interests \\ No competing interests were disclosed.}

Grant information

Mohsen Kayal's Ph.D. studies were supported by grants from Polynésienne des Eaux and Planète Urgence.

The funders had no role in study design, data collection and analysis, decision to publish, or preparation of the manuscript.

\section{Supplementary material}

Supplementary Image 1. Additional photographs capturing the predatory guild aggregating around a guarded coral following widespread coral decline. Pictures (a, b) were taken in August 2008 at $12 \mathrm{~m}$ depth on Tiahura reef in Moorea, French Polynesia, at the peak of an intense outbreak of the coral-eating crown-of-thorns seastar (COTS). The observed macro-predator aggregation was composed of one COTS and nine individuals from resident butterflyfish species Chaetodon ornatissimus, C. pelewensis, C. quadrimaculatus, C. reticulatus (see Figure 2). White feeding scars characteristic of recent COTS predation can be seen on the guarded coral (Pocillopora eydouxi).

Click here to access the data. 
Glynn PW: Some physical and biological determinants of coral community structure in the eastern Pacific. Ecol Monogr. 1976; 46(4): 431-456.

Publisher Full Text

Glynn PW: Fine-scale interspecific interactions on coral reefs: functional roles of small and cryptic metazoans. Smithson Contrib Mar Sci. 2013; 39: 229-248. Reference Source

Kayal M, Bosserelle P, Adjeroud M: Bias associated with the detectability of the coral-eating pest crown-of-thorns seastar and implications for reef management. $R$ Soc Open Sci. 2017; 4(8): 170396

PubMed Abstract | Publisher Full Text | Free Full Text

Kayal M, Kayal E: Colonies of the fire coral Millepora platyphylla constitute scleractinian survival oases during Acanthaster outbreaks in French Polynesia. Mar Biodivers. 2017; 47(1): 255-258.

Publisher Full Text

Kayal M, Lenihan HS, Pau C, et al:: Associational refuges among corals mediate impacts of a crown-of-thorns starfish Acanthaster planci outbreak. Coral Reefs. 2011; 30(3): 827-837.

Publisher Full Text

Kayal M, Vercelloni J, Lison de Loma T, et al.: Predator crown-of-thorns starfish (Acanthaster planci) outbreak, mass mortality of corals, and cascading effects on reef fish and benthic communities. PLoS One. 2012; 7(10): e47363.

PubMed Abstract | Publisher Full Text | Free Full Text

Leray M, Béraud M, Anker A, et al:: Acanthaster planci outbreak: decline in coral health, coral size structure modification and consequences for obligate decapod assemblages. PLoS One. 2012; 7(4): e35456.

PubMed Abstract | Publisher Full Text | Free Full Text

McKeon CS, Moore JM: Species and size diversity in protective services

offered by coral guard-crabs. PeerJ. 2014; 2: e574.

PubMed Abstract | Publisher Full Text | Free Full Text

Pratchett MS: Influence of coral symbionts on feeding preferences of crownof-thorns starfish Acanthaster planci in the western Pacific. Mar Ecol Prog Ser. 2001; 214: 111-119.

Publisher Full Text

Pratchett MS, Caballes CF, Rivera-Posada JA, et al.: Limits to understanding and managing outbreaks of crown-of thorns starfish (Acanthaster spp.). Oceanogr Mar Biol Annu Rev. 2014; 52: 133-200.

Reference Source

Rouzé H, Lecellier G, Mills SC, et al:: Juvenile Trapezia spp. crabs can increase juvenile host coral survival by protection from predation. Mar Ecol Prog Ser. 2014; 515: 151-159

Publisher Full Text

Silliman BR, McCoy MW, Angelini C, et al:: Consumer fronts, global change, and runaway collapse in ecosystems. Annu Rev Ecol Evol Syst. 2013; 44: 503-538. Publisher Full Text

Terborgh J, Estes JA: Trophic cascades: predators, prey, and the changing dynamics of nature. Island Press, Washington DC. 2010.

Reference Source 


\section{Open Peer Review}

\section{Current Peer Review Status:}

\section{Version 1}

Reviewer Report 07 February 2018

https://doi.org/10.5256/f1000research.14230.r30512

(c) 2018 Caballes C. This is an open access peer review report distributed under the terms of the Creative Commons Attribution License, which permits unrestricted use, distribution, and reproduction in any medium, provided the original work is properly cited.

\section{Ciemon Frank Caballes}

ARC Centre of Excellence for Coral Reef Studies, James Cook University, Townsville, Qld, Australia

This is an interesting observation of a relatively high concentration of a multi-species predator guild on corals that were initially spared from crown-of-thorns seastar (COTS) predation. The ultimate demise of "guarded" Pocilloporids may have been due to a high density of starving COTS (at the peak of an outbreak) feeding on whatever coral was left and overwhelming mutualistic crabs in the process. The overall impact of the butterflyfish, in terms of coral mortality, was most likely lower compared to COTS.

It is unclear whether this was a widespread occurrence or a one-time observation. A brief description of the feeding behaviour of COTS and butterflyfishes (relative contribution to coral mortality), as well as the defensive behaviour of Trapeziid crabs will be useful.

METHODS: Change Pocilloporida eydouxi to Pocillopora eydouxi.

SUPPLEMENTARY IMAGE 1: Feeding scars are not clear in the pictures.

Is the work clearly and accurately presented and does it cite the current literature? Yes

Is the study design appropriate and is the work technically sound? Yes

Are sufficient details of methods and analysis provided to allow replication by others? Partly

If applicable, is the statistical analysis and its interpretation appropriate? Not applicable

Are all the source data underlying the results available to ensure full reproducibility? 
Yes

Are the conclusions drawn adequately supported by the results?

Yes

Competing Interests: No competing interests were disclosed.

I confirm that I have read this submission and believe that I have an appropriate level of expertise to confirm that it is of an acceptable scientific standard.

Reviewer Report 12 December 2017

https://doi.org/10.5256/f1000research.14230.r27894

(C) 2017 Glynn P. This is an open access peer review report distributed under the terms of the Creative Commons Attribution License, which permits unrestricted use, distribution, and reproduction in any medium, provided the original work is properly cited.

\section{Peter W. Glynn}

Rosenstiel School of Marine and Atmospheric Science, Department of Marine Biology and Ecology, University of Miami, Miami, FL, USA

The alpheid shrimp guard, Alpheus lottini, also should be noted as defending pocilloporid corals from COTS attacks. This shrimp guard occurs world-wide on pocilloporid corals.

It would also be worth noting the defensive behaviour, if any, of the crustacean guards toward the fish corallivores.

'White feeding scars' are referred to in Fig. 1 and Fig. 2 (supplementary image). These are difficult to make out in the photographs. I suggest adding arrows to make these easier to see. Also, it would be useful to know the approximate diameters of the $P$. eydouxi colonies.

Is the work clearly and accurately presented and does it cite the current literature? Yes

Is the study design appropriate and is the work technically sound?

Yes

Are sufficient details of methods and analysis provided to allow replication by others? Yes

If applicable, is the statistical analysis and its interpretation appropriate? No

Are all the source data underlying the results available to ensure full reproducibility? Yes 
Are the conclusions drawn adequately supported by the results?

Yes

Competing Interests: No competing interests were disclosed.

Reviewer Expertise: Reef coral biology and ecology.

I confirm that I have read this submission and believe that I have an appropriate level of expertise to confirm that it is of an acceptable scientific standard.

The benefits of publishing with F1000Research:

- Your article is published within days, with no editorial bias

- You can publish traditional articles, null/negative results, case reports, data notes and more

- The peer review process is transparent and collaborative

- Your article is indexed in PubMed after passing peer review

- Dedicated customer support at every stage

For pre-submission enquiries, contact research@f1000.com 